\title{
The limiting pressure on a circular pile loaded laterally in cohesive soil
}

M. F. RANDOLPH and G. T. HOULSBY (1984). Géotechnique 34, No. 4, 613-623

Dr W. H. Ward, Consulting Engineer, Watford

As the Authors will be aware the solution to the plane strain problem in weightless plasticity theory is applicable also to the problem of the pressure on an upstanding obstacle in the track of a plastic mud flow, lava flow or avalanche. It aroused the Writer's interest in this context.

The solution is for a weightless material, although the Authors deal approximately with body forces at shallow depth by means of wedgetype failure.

During their study did the Authors examine the possibility of formally including body forces by adding a hydrostatic tension proportional to $z$ at each point of their stress solution?

The solution by Nye (1951) to the flow of a heavy plastic material down an inclined plane from the well-known Prandtl (1923) solution to weightless plastic flow between parallel plates is an example of such a treatment, admittedly in two dimensions.

\section{REFERENCES}

Nye, J. F. (1951). The flow of glacicrs and ice-sheets as a problem in plasticity. Proc. R. Soc. A 207, 554-572.
Prandtl, L. (1923). Anwendungsbeispiele zu einem Henckyschen Satz über das plastische Gleichgewicht. Z. Angew. Math. Mech. 3, 401.

\section{Authors' Reply}

The solution can indeed be applied to problems other than laterally loaded piles, and the case that the Writer cites of an obstacle in the path of a mud slide or other flowing material is a particularly interesting application.

In the lower bound solution, the normal stresses were written in terms of a reference stress $\sigma_{0}$. The Writer correctly implies that this stress may be expected to vary linearly with depth, reflecting the variation of in situ stresses. However, for a rigid plastic idealization of the soil, the solution will be independent of the initial stress state in the ground, and it would thus be incorrect to equate $\sigma_{0}$ directly with the initial horizontal stress in the ground, but a comparison of the decrease in normal stress on the trailing face of the pile with the in situ horizontal stress may give an indication of whether a gap is likely to form behind the pile. This might give an additional indication of the depth at which a wedge type of failure ahead of the pile transforms into flow around the pile. 